\title{
Article \\ A Comparative Study of Two-Minute versus Three-Minute Passive Recovery on Sprint Skating Performance of Ice Hockey Forwards and Defensemen
}

\author{
Arkadiusz Stanula ${ }^{1, *(\mathbb{D})}$, Subir Gupta ${ }^{2}$, Jakub Baron ${ }^{1}$, Anna Bieniec ${ }^{1}$, Rajmund Tomik ${ }^{1}{ }^{(D)}$, Tomasz Gabrys ${ }^{3}$, \\ Petr Valach $^{3}$ (D) and Andrzej Szymon Swinarew ${ }^{4}$ (D) \\ 1 Institute of Sport Sciences, Jerzy Kukuczka Academy of Physical Education, 40-065 Katowice, Poland; \\ j.baron@awf.katowice.pl (J.B.); a.bieniec@awf.katowice.pl (A.B.); r.tomik@awf.katowice.pl (R.T.) \\ 2 Faculty of Medical Sciences, Cave Hill Campus, University of West Indies, Bridgetown BB11000, Barbados; \\ subir.gupta@cavehill.uwi.edu \\ 3 Department of Physical Education and Sport, Faculty of Education, University of West Bohemia, \\ 30100 Pilsen, Czech Republic; tomaszek1960@o2.pl (T.G.); pvalach@ktv.zcu.cz (P.V.) \\ 4 Faculty of Science and Technology, University of Silesia in Katowice, 41-500 Chorzów, Poland; \\ andrzej.swinarew@us.edu.pl \\ * Correspondence: a.stanula@awf.katowice.pl; Tel.: +48-207-53-33
}

\section{check for} updates

Citation: Stanula, A.; Gupta, S.; Baron, J.; Bieniec, A.; Tomik, R.; Gabrys, T.; Valach, P.; Swinarew, A.S. A Comparative Study of Two-Minute versus Three-Minute Passive Recovery on Sprint Skating Performance of Ice Hockey Forwards and Defensemen. Int. J. Environ. Res. Public Health 2021, 18, 13029. https:// doi.org/10.3390/ijerph182413029

Academic Editor: Paul B. Tchounwou

Received: 12 November 2021 Accepted: 8 December 2021

Published: 10 December 2021

Publisher's Note: MDPI stays neutral with regard to jurisdictional claims in published maps and institutional affiliations.

Copyright: (c) 2021 by the authors. Licensee MDPI, Basel, Switzerland. This article is an open access article distributed under the terms and conditions of the Creative Commons Attribution (CC BY) license (https:/ / creativecommons.org/licenses/by/ $4.0 /)$.

\begin{abstract}
The impact of two different passive recovery durations, two and three minutes, between sets of repeated sprint skating ability (RSSA) test on skating speed, speed decrement $\left(\mathrm{S}_{\mathrm{dec}}\right)$, and heart rate $(H R)$ response of ice hockey forwards $(n=12)$ and defensemen $(n=7)$ were determined. Six sets of $3 \times 80 \mathrm{~m}$ sprint, with two-minute passive recovery between two consecutive sets, were performed in RSSA-2. A three-minute passive recovery period between two consecutive sets was allowed in RSSA-3. Skating speed, $S_{\mathrm{dec}}$, and HR were measured in all tests. Subjects skated faster $(p<0.05)$ in most of the RSSA-3 sets than the corresponding set of RSSA-2. Defensemen were slower $(p<0.05)$ than forwards in most of the cases. The $S_{\mathrm{dec}}$ was higher in defensemen than in forwards, although the difference was significant occasionally. No difference in peak HR and minimum HR between forwards and defensemen was found. RSSA-3 is beneficial over RSSA-2 in both forwards and defensemen by increasing speed. Defensemen are slower and show early fatigability than forwards, and no difference in HR response was noted between forwards and defensemen. This study concludes that three-minute recovery is beneficial over two-minute recovery by increasing skating speed, although $\mathrm{S}_{\mathrm{dec}}$ and HR response neither vary significantly between RSSA-2 and RSSA-3, nor between forwards and defensemen.
\end{abstract}

Keywords: heart rate; field test; skating performance; movement pattern; performance decrement; fatigue index

\section{Introduction}

Repeated sprint skating, quick changes in direction, and frequent profound body contact are some major characteristics of the game of ice hockey. A standard ice hockey match is actually played for $60 \mathrm{~min}$, which is made up of three $20 \mathrm{~min}$ periods. The total time of play, however, often extends much longer, including two rest intervals [1-3]. To keep the game fast, frequent substitution of players is a common practice in ice hockey matches. On average, an ice hockey player effectively plays for 15 to $24 \mathrm{~min}$, which is relatively shorter than players of most other team sports of comparable duration [4]. In ice hockey matches, the players do not play continuously but alternate at nearly regular intervals, commonly known as a "shift". The duration of each shift usually varies from 30 to $80 \mathrm{~s}$, interspersed with 2 to $5 \mathrm{~min}$ of passive recovery [4].

Ice hockey players of various playing positions experience different workloads that can reflect their physiological profiles. Researchers conducted a number of studies on physical- 
and physiological profiles of ice hockey players in relation to their position of play [5-7]. Researchers reported similar aerobic capacity in ice hockey forwards and defensemen, but lower values in goalkeepers [5,8-10]. Similarly, difference in body composition and anthropometric parameters were also reported on ice hockey players of different playing positions [5].

Sport scientists and trainers have designed a number of repeated sprint ability (RSA) tests based on the movement patterns and speed at the intense period of competitive match play in team sports [11-15]. Despite an exponential increased interest, the physiological basis of drop-off performance in RSA test remains obscured [16]. Repeated sprint performance, however, is useful in guiding and implementing appropriate training that likely improves match performance by deferring fatigue [17].

Several on-ice RSA tests, on a wide range of ice hockey players, have been introduced by sports scientists and strength and conditioning coaches. Repeated sprint skating ability (RSSA) test was designed in this study to replicate some of the basic movement patterns and recovery period during ice hockey match play. Duration of recovery period or bench time, between shifts of play, are expected to play an important role in the extent of recovery and thus skating performance during the shift of play. Replacement of the players, or rest period between shifts, are strategic and aimed to allow the players to recover sprint ability [9]. However, to the best of our knowledge, no such studies were carried out on the ice hockey players that show the effect of different recovery period duration on players of different positions in real match play or any form of RSSA tests.

This study is designed to mimic some basic movement patterns and passive recovery period of ice hockey game with RSSA protocol. The major aim of this study is to determine the effect of two different durations of recovery periods, 2 min (or RSSA-2) and $3 \mathrm{~min}$ (or RSSA-3), between successive sets of repeated sprint skating ability test. The impact of the recovery period duration on the skating performance of ice hockey forwards and defensemen was studied by analyzing average skating speed, speed decrement $\left(S_{\text {dec }}\right)$, and heart rate during RSSA-2 and RSSA-3 tests.

\section{Materials and Methods}

\subsection{Subjects}

All the subjects of this study were selected from the club Zagłębie Sosnowiec, participating in the highest ice hockey league in Poland. Uninjured outfield players (12 forwards, 7 defensemen), having a minimum experience of 7 years of playing ice hockey, and those who participated at least $90 \%$ of the training sessions, were finally selected as the subjects for this study. Players were training in a regular scheme of off-season macrocycle, which involved 2-3 gym sessions per week and lasted about $60 \mathrm{~min}$, with average RPE around 7 (in 1-10 scale). They had also one functional-prehab training, lasting around $30 \mathrm{~min}$ with average RPE of 3.

\subsection{Main Test Procedures}

\subsubsection{Study Design}

This study was conducted in the preseason of 2020, over 4 nonconsecutive days. On day 1 , height, body weight, and body composition of the subjects were measured. Skating Multistage Aerobic Test (SMAT) was used to determine maximum heart rate ( $\left.\mathrm{HR}_{\max }\right)$ and predict $\mathrm{VO}_{2 \max }$ on day 2 . On days 3 and 4 (separated by 5 days), repeated sprint skating ability (RSSA), by using two different durations of passive recovery period ( 2 and $3 \mathrm{~min}$ ) between sets of RSSA were measured. Experiments on days 2, 3, and 4 were conducted at the same time of the day (10 a.m. to 1 p.m. and 6 p.m. to 9 p.m.). Subjects were informed to abstain from training and any other forms of heavy physical exercise for $24 \mathrm{~h}$ before the experiment. They were also instructed to maintain normal diet and fluid intake. The protocol and possible risks involved in the study were explained to the subjects before they gave voluntary written informed consent. The study was approved by the Ethics 
Committee of the Jerzy Kukuczka Academy of Physical Education in Katowice (approval number: 8/2018).

\subsubsection{Measurement of Body Composition}

Body composition analyzer (InBody170, Biospace, Seoul, Korea) was used to determine body mass and height, total muscle mass, fat mass, and total body water of the subjects. All the subjects were tested at least $4 \mathrm{~h}$ after a meal, in empty bladder condition and at normal room temperature $\left(20-23{ }^{\circ} \mathrm{C}\right)$.

2.2.3. Measurement of Maximum Heart Rate and Predicted $\mathrm{VO}_{2 \max }$ by Skating Multistage Aerobic Test (SMAT)

Leone et al. [18] originally designed this on-ice test. The test was conducted on an indoor ice hockey rink, defined with markers at both extremities. The subject skated from one end to the other holding the hockey stick with the preferred one hand. The speed was increased gradually till he was unable to maintain it. The pace of the subject was dictated by audible signals emitted from a calibrated audio player. The starting speed was $3.5 \mathrm{~m} \cdot \mathrm{s}^{-1}$, followed by stepwise increment by $0.2 \mathrm{~m} \cdot \mathrm{s}^{-1}$. A passive recovery period of $30 \mathrm{~s}$ was allowed before the next sprint was started. The following formula was used to predict $\mathrm{VO}_{2 \max }$ of the subject [18]:

$$
\mathrm{VO}_{2 \max }=18.07 \times\left(\text { maximum velocity in } \mathrm{m} \cdot \mathrm{s}^{-1}\right)-35.596 \mathrm{~mL} \cdot \mathrm{kg}^{-1} \cdot \mathrm{min}^{-1}
$$

\subsubsection{Repeated Sprint Skating Ability (RSSA) Test}

Based on the movement pattern and duration of each sprint of the players found during ice hockey match play, Hůlka et al. [14] originally designed this test. Subjects were familiar with this test. They were required to perform 6 sets of sprint trials. Each set of sprint trial was composed of a $3 \times 80 \mathrm{~m}$ sprint. The direction of skating of each repetition of sprint is shown in Figure 1a. Each repetition of sprint consisted of $18 \mathrm{~m}$ of skating forward straight from the goal line, stopping at blue line ( $2 \mathrm{~m}$ from barrier), followed by skating backward $22 \mathrm{~m}$ on the goal line, then skating forward $22 \mathrm{~m}$ up to blue line, followed by sharp right turn towards the goal line and the last $18 \mathrm{~m}$ skating forward to finish at the goal line. Thus, the total distance covered in each repetition of sprint was $80 \mathrm{~m}$. After each repetition of sprint, the subject had to go back at the starting point by skating (mainly gliding) slowly. A $30 \mathrm{~s}$ passive recovery (including the slow skating time from the end point of one sprint trial to the beginning of the next) separated two consecutive sprints. Photocell automatic laser timing system (Mircrogate, Racetime 2, Bolzano, Italy) was used to measure sprint performance of the subject. Hand stopwatch was used to measure passive recovery period.

The subject performed two types of RSSA tests based on the durations of the passive recovery period:

RSSA-2: The passive recovery period between two consecutive sets was $2 \mathrm{~min}$;

RSSA-3: The duration of the recovery period between two sets was $3 \mathrm{~min}$.

Speed Decrement $\left(\mathrm{S}_{\mathrm{dec}}\right)$

The speed decrement (\%) in any given set of RSSA test was calculated by using the following formula [13]:

$$
\mathrm{S}_{\mathrm{dec}}(\%)=\left[(\mathrm{S} 1+\mathrm{S} 2+\mathrm{S} 3) /\left(3 \times \mathrm{S}_{\text {best }}\right)-1\right] \times 100
$$

where $\mathrm{S} 1$ to $\mathrm{S} 3$ are times of 3 sprint repetitions in a set, and $\mathrm{S}_{\text {best }}$ is the best sprint time in a set. 


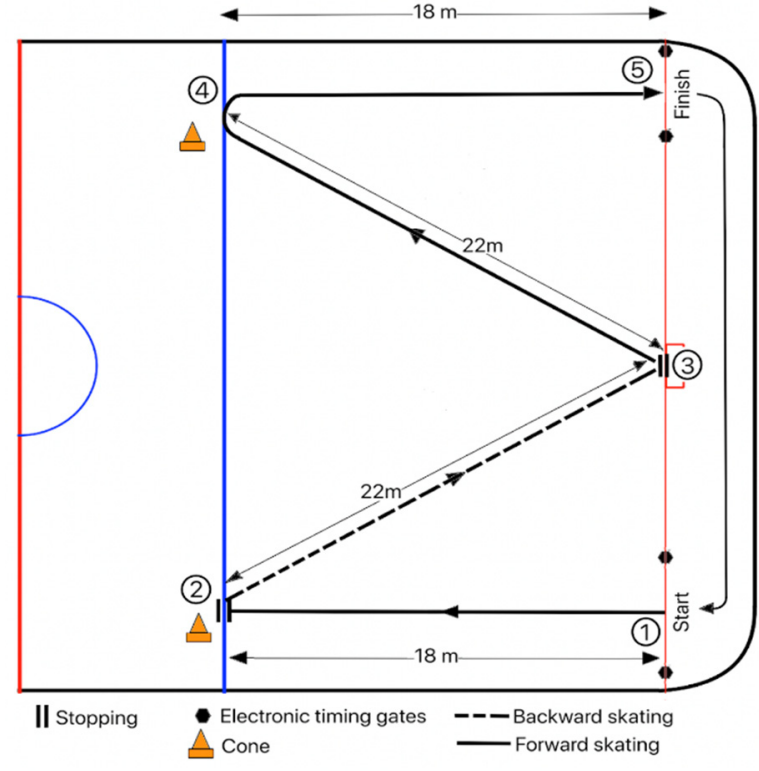

(a)
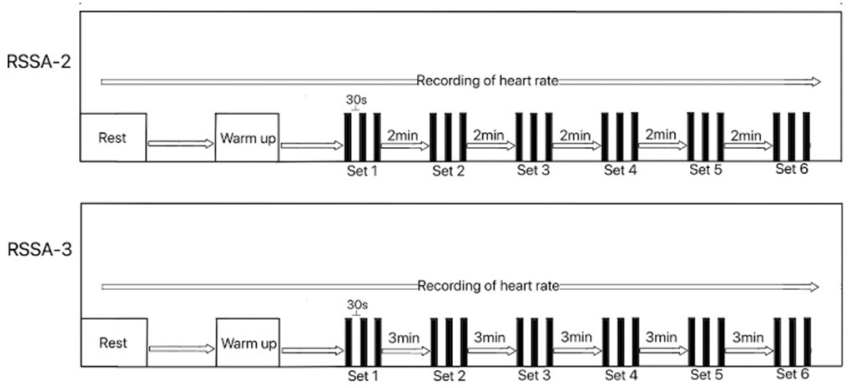

(b)

Figure 1. (a) Direction and distance of sprint skating in the repeated sprint skating ability test; (b) Schematic presentation of the overall study protocol. It illustrates 6 sets of RSSA tests with two different recovery periods between the sets-RSSA-2, with recovery period of $2 \mathrm{~min}$, and RSSA-3, with recovery period of $3 \mathrm{~min}$. It also shows that heart rate was recorded continuously, starting from rest till the end of the 6th set of both RSSA-2 and RSSA-3 tests.

\section{Warm-Up before RSSA Test}

Duration and activities in warm-up in both RSSA-2 and RSSA-3 were similar. The subject warmed up for $20 \mathrm{~min}$, which consisted of 15 and $5 \mathrm{~min}$ of off-ice and on-ice activities, respectively, spaced by about $20 \mathrm{~min}$ rest to put on hockey gear. The off-ice warm-up involved raising body temperature, mobilizing joints, activating muscles, and potentiating nervous system [19]. The on-ice warm-up comprised of alternating interplay of fast- and slow skating.

\section{Recording of Heart Rate}

Heart rate telemeter (Polar Team2, Polar Electro Oy, Kempele, Finland) was used to record heart rate, during SMAT, at an interval of $2 \mathrm{~s}$. In RSSA tests, HR was recorded at an interval of $2 \mathrm{~s}$, from warm-up till the end of the Set 6 .

\subsection{Statistical Analysis}

To represent the average and the typical spread of values of all measurable variables, mean and standard deviation (SD) were used. Shapiro-Wilk test was used to verify the normal Gaussian distribution of the data. Levene's and Mauchly's tests were used to test homoscedasticity and sphericity of data, respectively. To determine differences between forwards and defensemen, Student's $t$-test for independent samples was used for normally distributed data and equal variances, the t-Student test with Cochran-Cox adjustment in case of normally distributed data but unequal variances and the U-Mann-Whitney test for non-normally distributed data. The effect size (ES) of the intervention was calculated using Cohen's guidelines. Threshold values for ES were $>0.2$ (small), $>0.6$ (moderate), $>1.2$ (large), and $>2.0$ (very large) [20]. To investigate differences in variables, a two-way analysis of variance with repeated measures and HSD (Honestly Significant Difference) Tukey-Kramer post hoc analysis was used. Statistical significance was set at $p \leq 0.05$. All statistical analyses were conducted using Statistica 13.3 (TIBCO Software Inc., Palo Alto, CA, USA). 


\section{Results}

\subsection{Physical and Physiological Characteristics of the Subjects}

Table 1 presents age, height, weight, muscle mass, body fat percentage, predicted $\mathrm{VO}_{2 \max }$, and $\mathrm{HR}_{\max }$ of the subjects. Defensemen are taller $(\mathrm{ES}=$ Small), heavier $(\mathrm{ES}=$ moderate), have marginally higher body fat $\%(E S=$ Small $)$ and muscle mass ( $E S=$ Moderate), and lower $\mathrm{VO}_{2 \max }(\mathrm{ES}=$ small $)$ than their forward counterparts.

Table 1. Physical characteristics of the volunteers.

\begin{tabular}{cccccc}
\hline Variables & $\begin{array}{c}\text { Forwards } \\
(\mathbf{n}=\mathbf{1 2})\end{array}$ & $\begin{array}{c}\text { Defensemen } \\
(\mathbf{n}=\mathbf{7})\end{array}$ & $\boldsymbol{\Delta} \mathbf{( \% )}$ & $p$-Value & Effect Size \\
\hline Age & $23.4 \pm 4.76$ & $22.3 \pm 5.2$ & $1.2(5.1 \%)$ & 0.582 & $0.24 / \mathrm{Small}$ \\
Height $(\mathrm{cm})$ & $179.8 \pm 5.68$ & $182.0 \pm 3.46$ & $-2.2(-1.2 \%)$ & 0.331 & $0.43 /$ Small \\
Weight $(\mathrm{kg})$ & $80.5 \pm 7.57$ & $87.1 \pm 4.81$ & $-6.6(-8.2 \%)$ & 0.036 & $0.97 / \mathrm{Moderate}$ \\
Body fat\% & $14.9 \pm 4.75$ & $17.3 \pm 3.08$ & $-2.4(-16.1 \%)$ & 0.208 & $0.56 /$ Small \\
Muscle $\mathrm{mass}(\mathrm{kg})_{\text {Pred } \mathrm{VO}_{2 \max }\left(\mathrm{ml} \cdot \mathrm{kg}^{-1} \cdot \mathrm{min}^{-1}\right)}^{39.2 \pm 4.02}$ & $41.4 \pm 2.19$ & $-2.2(-5.5 \%)$ & 0.171 & $0.61 /$ Moderate \\
$\mathrm{HR}_{\max }(\mathrm{bpm})$ & $52.3 \pm 3.11$ & $50.7 \pm 6.24$ & $1.6(3.1 \%)$ & 0.398 & $0.37 /$ Small \\
\hline
\end{tabular}

\subsection{RSSA-2- and RSSA-3 Test Performance}

Average skating speed of the forwards and defensemen in RSSA-2 and RSSA- 3 tests is presented in Figure 2. Forwards performed both RSSA-2 and RSSA-3 faster than defensemen (the upper panel of Figure 2). The average skating speed of the forwards was significantly $(p<0.05)$ higher than the Defensemen in most of the sets of RSSA-2, except Sets 1 and 2 . The difference of skating speed between forwards and defensemen; however, was not significant in RSSA-3. The lower panel of Figure 2 compares the skating performance of the subjects between RSSA-2 and RSSA-3 tests. Except in Set 1, subjects of both the playing positions skated much faster $(p<0.05)$ in RSSA-3 in comparison to RSSA-2.

\subsection{Speed Decrement}

Figure 3 shows $S_{\text {dec }}$ of the forwards and the defensemen in RSSA- 2 and RSSA- 3 tests. The $S_{\text {dec }}$ is higher in RSSA-2 than RSSA-3, for any given set (except set 1 ), in both forwards and defensemen (the lower panel, Figure 3). The difference, however, is non-significant in all the cases. Defensemen showed higher $S_{\text {dec }}$ than forwards in all the sets, although the difference was significant only in the Set 1 of RSSA-3 (the upper panel, Figure 3).

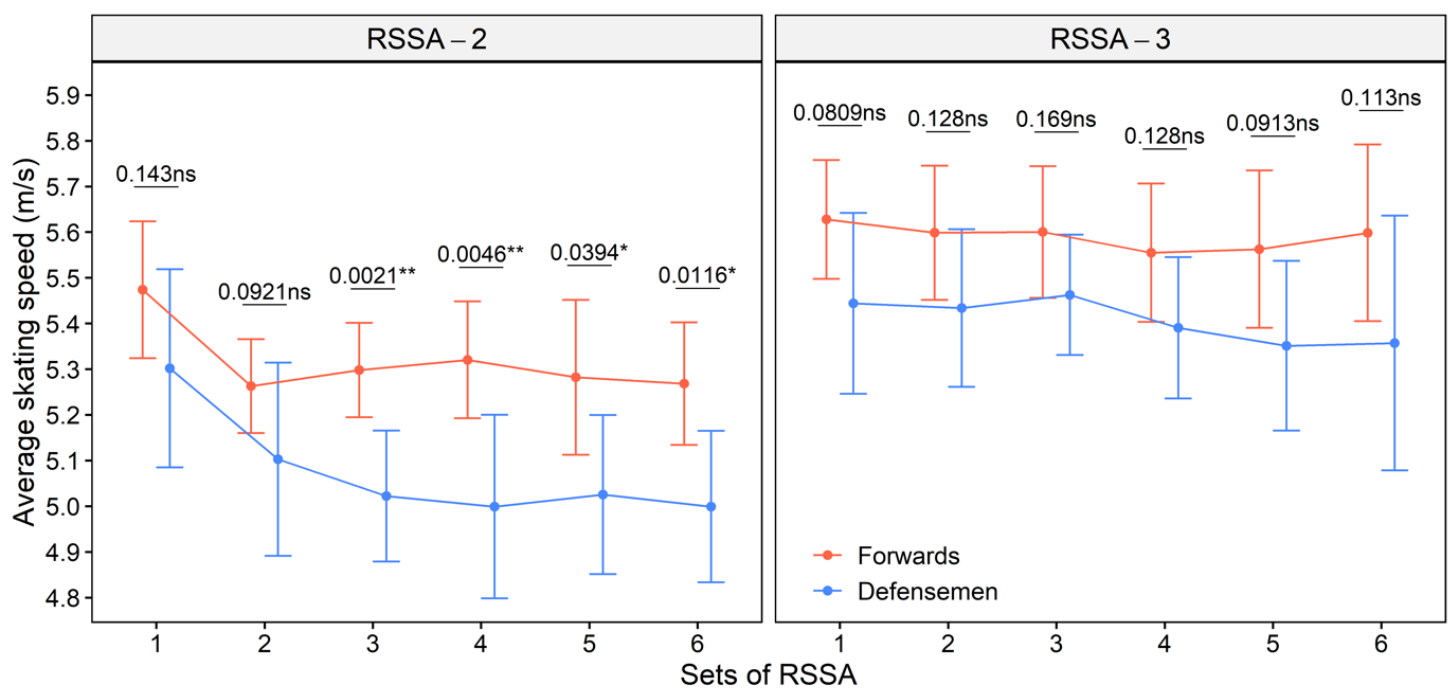

Figure 2. Cont. 


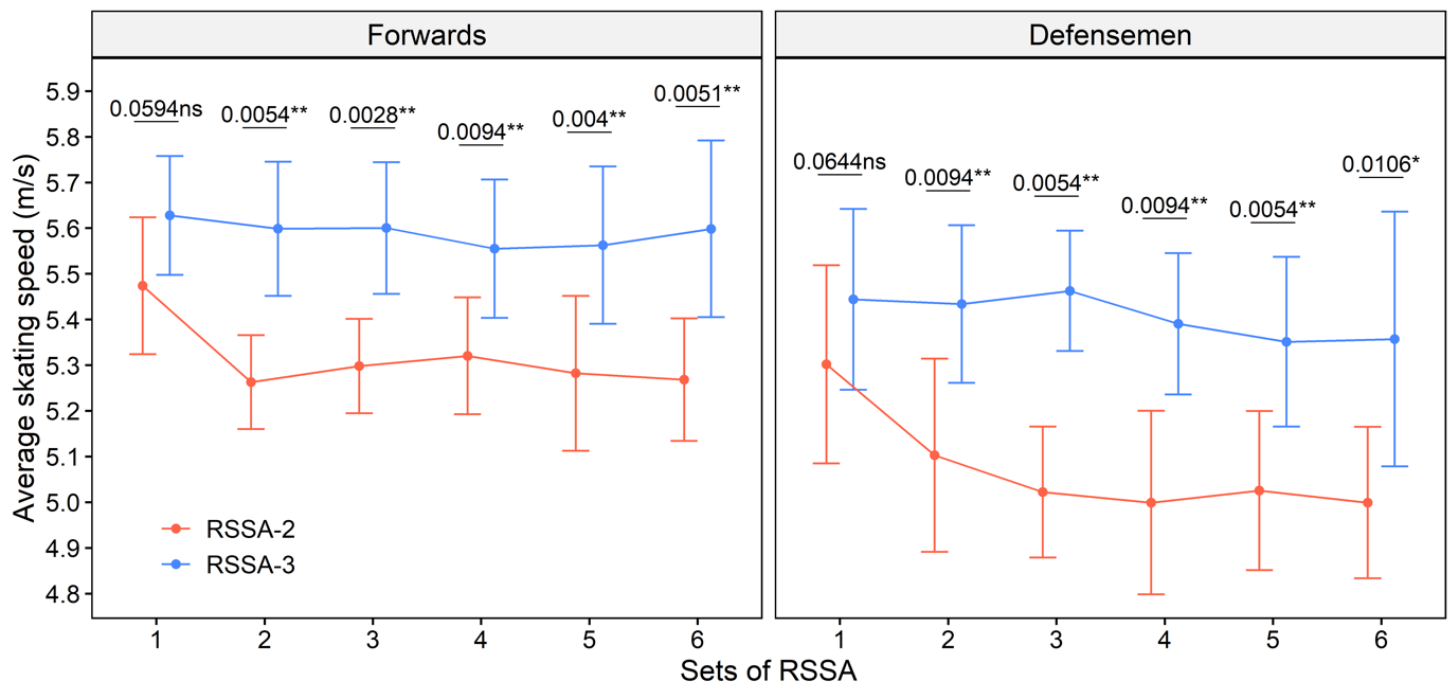

Figure 2. Average skating speed of the forwards and defensemen in RSSA-2 and RSSA-3 tests (ns—non-significant, ${ }^{*} p<0.05$; ** $p<0.01)$.
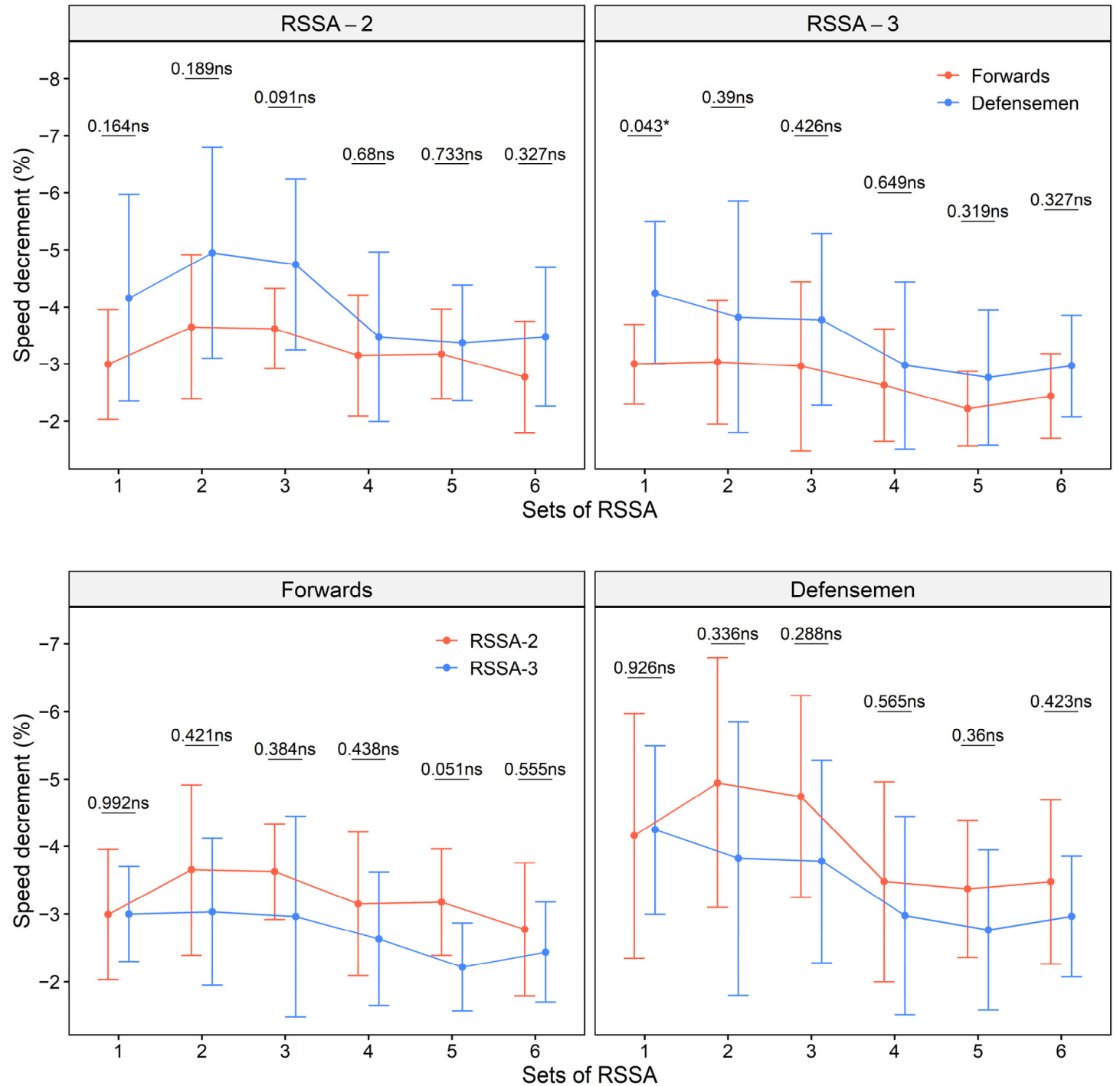

Figure 3. Speed decrement of the forwards and defensemen in RSSA-2 and RSSA-3 tests (ns-non-significant; ${ }^{*} p<0.05$ ). 


\subsection{Heart Rate Response}

Peak heart rate and $\mathrm{HR}_{\min }$ attained in the subjects during RSSA- 2 and RSSA- 3 tests are presented in Figure 4. No difference in $\mathrm{HR}_{\text {peak }}$ was found between forwards and defensemen, and both attained highest $\mathrm{HR}_{\text {peak }}$ (forwards $94.9 \pm 2.7$ and $94.1 \pm 2.2 \% \mathrm{HR}_{\max }$ in RSSA-2 and RSSA-3 respectively; defensemen $93.5 \pm 3.5$ and $92.9 \pm 3.2 \% \mathrm{HR}_{\max }$ in RSSA-2 and RSSA-3, respectively) mostly in Set 6. Only a marginal rise in $H_{\text {peak }}$ was observed from Set 1 through 6 . However, $\mathrm{HR}_{\min }$ increased significantly higher from Set 1 through 6 in both forwards and defensemen.
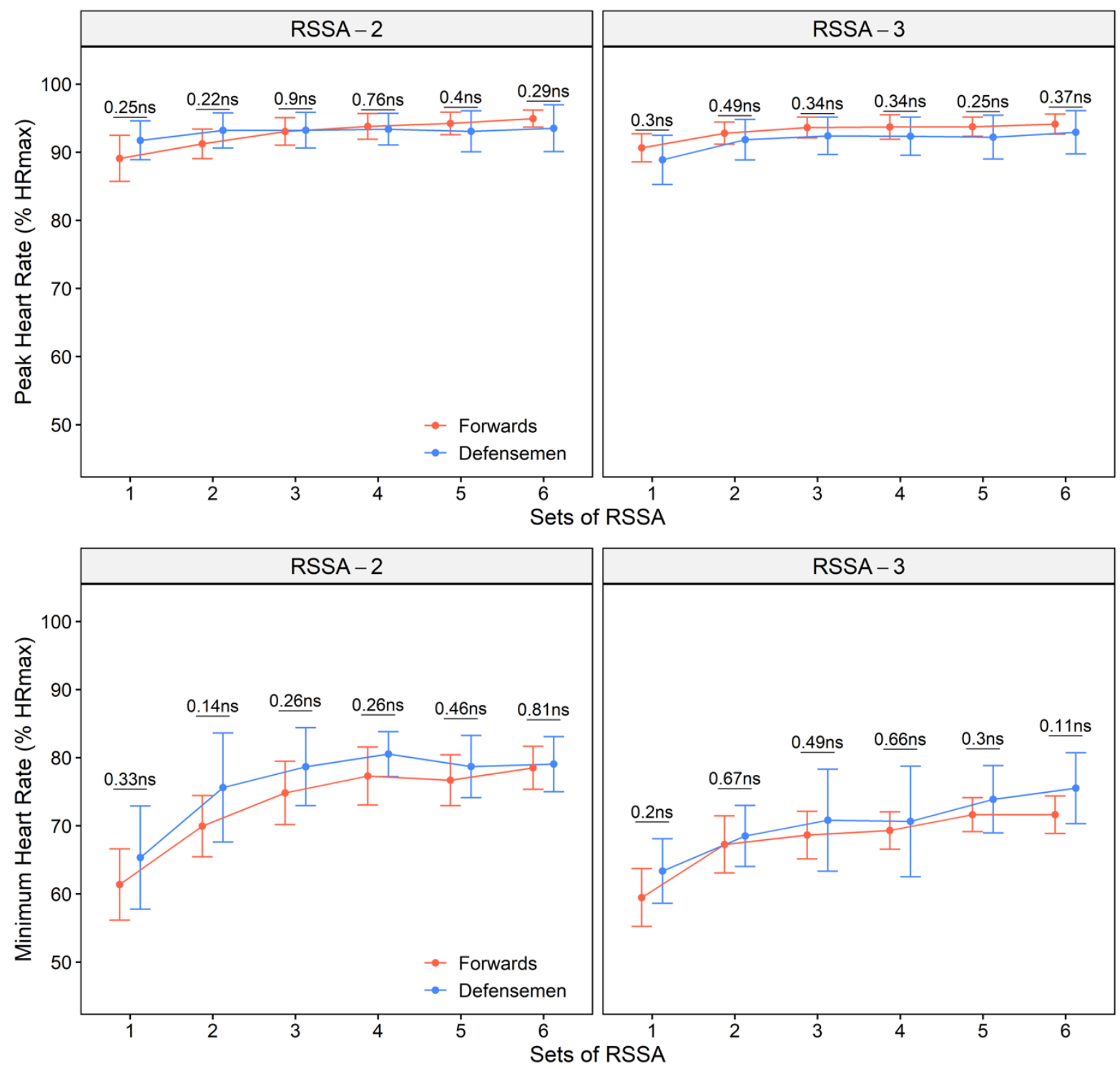

Figure 4. Peak HR and minimum HR of the forwards and defensemen during various sets of RSSA-2 (above) and RSSA-3 (below) tests (ns-non-significant).

\section{Discussion}

The major finding of this study is that the recovery period of $3 \mathrm{~min}$ (RSSA-3) between sets of repeated sprint causes both forwards and defensemen to skate faster and reduce $S_{\text {dec }}$ when compared to a two minute recovery (RSSA-2). The forwards skate faster and show lower $S_{\text {dec }}$ than defensemen, but HR response is similar in both forwards and defensemen.

The $\mathrm{VO}_{2 \max }$ of the participants of this study is like the top Polish ice hockey players [21], but inferior to ice hockey players of an elite category [1]. Lean body mass is one 
of the essential requirements for ice hockey players to support sprint and for optimizing performance, rapid change of direction, balance, agility, and frequent high impact body contact $[10,22]$. Higher division players were found to contain relatively lower body fat than lower division players of NCAA [23]. Twist et al. [10] reported that ice hockey goalkeepers contain higher body fat (13.5\%) than defensemen $(12.1 \%)$ and forwards $(10.8 \%)$. The fat content of the subjects in this study is higher than elite ice hockey players, but similar to top Polish ice hockey players, as studied by Roczniok et al. [21]. Preseason measurement is one of the likely causes of higher body fat of the subjects in this study. Although excess fat and body mass are protective against collision during the game, these are major obstacles for skating due to increased frictional resistance on the ice [22]. Like many other studies, Defensemen in the present study also show higher body fat than forwards [22]. Higher physiological demand and training specificity are responsible for difference in body composition between forwards and defensemen [22].

Results show that a three minute passive recovery made a significant difference over a two minute recovery on average speed, but have moderate to low impact on $S_{\mathrm{dec}}$, and heart rate response in the subjects. An important fitness demand of an ice hockey player is the capability to recover quickly and to perform adequately in subsequent skating sprints [13]. For repeated sprint skating, phosphocreatine is the most important and immediate source of energy. The contribution of the oxidative phosphorylation is limited $(<10 \%)$ during a single short sprint $[24,25]$. However, the magnitude of aerobic contribution increases progressively with repetitions of sprint and may contribute up to $40 \%$ of the total ATP generated in the final stage of a repetitive sprint exercise [24].

A large depletion of phosphocreatine occurs immediately after repeated sprint exercise, and longer than five minutes may be required for complete recovery of the phosphocreatine back to the pre-exercise level $[26,27]$. So, it is likely that only partial restoration of phosphocreatine takes place during two and three minute recovery period between the sets of RSSA. It is also expected that the recovery of phosphocreatine is more at the end of the three minute rest period than at the end of a two minute one. Gradual depletion of phosphocreatine at the beginning of subsequent sets of RSSA is likely to be an important factor that contributes to sprint decrement in the players.

Fatigue index (FI) and $S_{\text {dec }}$ are two terms commonly used by researchers to quantify the capacity to resist fatigue and drop-off performance [16]. Speed decrement is possibly preferred over FI for the reason that FI is calculated from the drop-off in speed from the best to the worst, whereas $S_{\text {dec }}$ considers all sprints $[11,28]$. So, $S_{d e c}$ may be lower in a set where all the repetitions are executed slowly. This may explain why the difference in $S_{\text {dec }}$ between RSSA-2 and RSSA-3 was only marginal.

Peak HR in competitive ice hockey match play often exceeds $90 \%$ of $\mathrm{HR}_{\max }$, whereas $\mathrm{HR}_{\mathrm{aver}}$ varies around $85 \%$ of $\mathrm{HR}_{\max }$ [22,29]. Gradual increase of $\mathrm{HR}$ with the progression of RSSA reflects the involvement of more energy from aerobic source during latter sets. The maximal cardiac workload in both the forms of RSSA is similar as indicated by similar $\mathrm{HR}_{\text {peak }}$, although the subjects experienced lower $\mathrm{HR}_{\min }$ in RSSA-3. Shorter passive recovery in RSSA-2 is responsible for elevated HR before the next set begins. Relatively higher circulating plasma catecholamines before the onset of a set in RSSA-2 may be responsible for higher $\mathrm{HR}_{\min }$ in RSSA-2 than in RSSA-3. Catecholamines, however, are short-lived signaling molecules in plasma [30], and their complete removal from circulation is unlikely to occur even three minutes after the end of a set.

The defensemen in this study were slower than forwards in both the formats and all the sets of RSSA test. Higher body weight, game demand, and training pattern of defensemen likely cause slower skating speed than forwards. Defensemen play longer than forwards in ice hockey match play due to higher number of shifts and thus shorter recovery period between the shifts [3,29]. Much slower skating speed also recorded in defensemen than Forwards during match play [3]. The game demand and difference in training may be other factors responsible for difference in average speed of the defensemen. However, despite faster repeated skating by the forwards, the $\mathrm{HR}_{\mathrm{aver}}$ remains similar or 
marginally lower than defensemen. Superior endurance capacity of forwards may cause this result. Researchers reported very high $\mathrm{HR}_{\text {aver }}$ and $\mathrm{HR}_{\text {peak }}$ values both in forwards and defensemen during ice hockey match play, but show no significant difference between players of two different playing positions. Forwards and defensemen reported playing a match with $\mathrm{HR}_{\text {aver }}$ of 161 and $158 \mathrm{bpm}$, respectively, and attained $\mathrm{HR}_{\text {peak }}$ of 195.4 and $196.6 \mathrm{bpm}$, respectively $[29,31]$. In spite of slower movement than forwards, defensemen gave their maximum possible performance as indicated by $\mathrm{HR}_{\mathrm{aver}}$.

\subsection{Future Research Directions}

To the best of our knowledge, studies on the effects of passive recovery period duration on the skating performance of ice hockey players are not known. Recovery period between two shifts of competitive ice hockey match play varies widely. This study can open a new avenue where the effects of various other recovery period durations (e.g., 2 versus $4 \mathrm{~min}, 3$ versus $5 \mathrm{~min}, 3$ versus $4 \mathrm{~min}$ ) can be conducted. This can help coaches and players to find out the ideal bench time (or passive recovery time) in terms of maximum physiological benefits without affecting match strategies. A similar assessment of the sprint times and drop-off in repeated sprints efforts of the on-ice shift times would be informative for coaches. Moreover, similar studies can be conducted on ice hockey players of various levels.

\subsection{Limitations}

Low number of subjects, especially defensemen, is one of the major limitations of this study. Heart rate is the only physiological variable used in this study to analyze and compare stress in the two formats of repeated skating tests (i.e., RSSA-2 and RSSA-3). Observation and analysis of other variables like lactate, cortisol, and catecholamines can explain the metabolic basis of the findings of the study.

\section{Conclusions}

The results of the present study conclude (1) the benefits of a three-minute recovery period (RSSA-3), over two minutes (RSSA-2), in both forwards and defensemen by increasing the average skating speed, (2) forwards are faster and show slower drop-off performance than defensemen, and (3) HR response does not vary between forwards and defensemen during repeated sprint skating.

Author Contributions: Conceptualization, J.B., S.G. and A.S.; Methodology, J.B., S.G., A.B. and A.S.; Validation, S.G., A.S., R.T., T.G. and A.S.S.; Formal analysis, J.B., A.S. and A.S.S.; Investigation, J.B., S.G., A.B. and A.S.; Writing—original draft preparation, S.G., A.S., and J.B.; Writing-review and editing, T.G., P.V., R.T., A.S.S. and A.B.; Visualization, A.S. and S.G.; Supervision, A.S., S.G., J.B. and T.G.; Project administration, J.B., A.S., S.G., R.T. and A.S.S. All authors have read and agreed to the published version of the manuscript.

Funding: Financed by the Jerzy Kukuczka Academy of Physical Education, Katowice 40-065, Poland.

Institutional Review Board Statement: The study was conducted according to the guidelines of the Declaration of Helsinki, and approved by the University Bioethics Committee for Research at The Jerzy Kukuczka Academy of Physical Education in Katowice (No. 8/2018).

Informed Consent Statement: Informed consent was obtained from all subjects involved in the study.

Conflicts of Interest: The authors declare no conflict of interest.

\section{References}

1. Burr, J.F.; Jamnik, R.K.; Baker, J.; Macpherson, A.; Gledhill, N.; McGuire, E.J. Relationship of physical fitness test results and hockey playing potential in elite-level ice hockey players. J. Strength Cond. Res. 2008, 22, 1535-1543. [CrossRef] [PubMed]

2. Cox, M.H.; Miles, D.S.; Verde, T.J.; Rhodes, E.C. Applied Physiology of Ice Hockey. Sports Med. 1995, 19, 184-201. [CrossRef]

3. Green, H.; Bishop, P.; Houston, M.; McKillop, R.; Norman, R.; Stothart, P. Time motion and physiological assessments of ice hockey performance. J. Appl. Physiol. 1976, 40, 159-163. [CrossRef] 
4. Brocherie, F.; Girard, O.; Millet, G.P. Updated analysis of changes in locomotor activities across periods in an international ice hockey game. Biol. Sport 2018, 35, 261-267. [CrossRef] [PubMed]

5. Agre, J.C.; Casal, D.C.; Leon, A.S.; McNally, C.; Baxter, T.L.; Serfass, R.C. Professional ice hockey players: Physiologic, anthropometric, and musculoskeletal characteristics. Arch. Phys. Med. Rehabil. 1988, 69, 188-192.

6. Geithner, C.A.; Lee, A.M.; Bracko, M.R. Physical and performance differences among forwards, defensemen, and goalies in elite women's ice hockey. J. Strenght Cond. Res. 2006, 20, 500-505. [CrossRef]

7. Houston, M.E.; Green, H.J. Physiological and anthropometric characteristics of elite Canadian ice hockey players. J. Sports Med. Phys. Fitness 1976, 16, 123-128. [PubMed]

8. Bracko, M.R.; George, J.D. Prediction of Ice Skating Performance with Off-Ice Testing in Women's Ice Hockey Players. J. Strength Cond. Res. 2001, 15, 116-122. [CrossRef]

9. Stanula, A.; Roczniok, R.; Maszczyk, A.; Pietraszewski, P.; Zajac, A. The role of aerobic capacity in high-intensity intermittent efforts in ice-hockey. Biol. Sport 2014, 31, 193-195. [CrossRef]

10. Twist, P.; Rhodes, T. Exercise physiology: A physiological analysis of ice hockey positions. Natl. Strength Cond. Assoc. J. 2008, 15, 44-46. [CrossRef]

11. Bishop, D.; Spencer, M.; Duffield, R.; Lawrence, S. The validity of a repeated sprint ability test. J. Sci. Med. Sport 2001, 4, 19-29. [CrossRef]

12. Da Silva, J.F.; Guglielmo, L.G.A.; Bishop, D. Relationship between different measures of aerobic fitness and repeated-sprint ability in elite soccer players. J. Strength Cond. Res. 2010, 24, 2115-2121. [CrossRef] [PubMed]

13. Girard, O.; Mendez-Villanueva, A.; Bishop, D. Repeated-sprint ability part I: Factors contributing to fatigue. Sports Med. 2011, 41, 673-694. [CrossRef] [PubMed]

14. Hůlka, K.; Bělka, J.; Cuberek, R.; Schneider, O. Reliability of specific on-ice repeated-sprint ability test for ice-hockey players. Acta Gymnica 2014, 44, 69-75. [CrossRef]

15. Rampinini, E.; Sassi, A.; Morelli, A.; Mazzoni, S.; Fanchini, M.; Coutts, A.J. Repeated-sprint ability in professional and amateur soccer players. Appl. Physiol. Nutr. Metab. 2009, 34, 1048-1054. [CrossRef]

16. Oliver, J.L. Is a fatigue index a worthwhile measure of repeated sprint ability? J. Sci. Med. Sport 2009, 12, 20-23. [CrossRef] [PubMed]

17. Glaister, M. Multiple sprint work: Physiological responses, mechanisms of fatigue and the influence of aerobic fitness. Sport. Med. 2005, 35, 757-777. [CrossRef]

18. Leone, M.; Léger, L.A.; Larivière, G.; Comtois, A.S. An on-ice aerobic maximal multistage shuttle skate test for elite adolescent hockey players. Int. J. Sports Med. 2007, 28, 823-828. [CrossRef]

19. McGowan, C.J.; Pyne, D.B.; Thompson, K.G.; Rattray, B. Warm-Up Strategies for Sport and Exercise: Mechanisms and Applications. Sports Med. 2015, 45, 1523-1546. [CrossRef]

20. Hopkins, W.G.; Marshall, S.W.; Batterham, A.M.; Hanin, J. Progressive statistics for studies in sports medicine and exercise science. Med. Sci. Sport. Exerc. 2009, 41, 3-13. [CrossRef]

21. Roczniok, R.; Stanula, A.; Gabryś, T.; Szmatlan-Gabryś, U.; Gołaś, A.; Stastny, P. Physical fitness and performance of polish ice-hockey players competing at different sports levels. J. Hum. Kinet. 2016, 50, 201-208. [CrossRef] [PubMed]

22. Montgomery, D.L. Physiology of ice hockey. Sports Med. 1988, 5, 99-126. [CrossRef]

23. Peterson, B.J.; Fitzgerald, J.S.; Dietz, C.C.; Ziegler, K.S.; Ingraham, S.J.; Baker, S.E.; Snyder, E.M. Aerobic capacity is associated with improved repeated shift performance in hockey. J. Strength Cond. Res. 2015, 29, 1465-1472. [CrossRef]

24. McGawley, K.; Bishop, D. Anaerobic and aerobic contribution to two, $5 \times 6$-s repeated-sprint bouts. Coach. Sport Sci. J. $2008,3,52$.

25. Parolin, M.L.; Chesley, A.; Matsos, M.P.; Spriet, L.L.; Jones, N.L.; Heigenhauser, G.J.F. Regulation of skeletal muscle glycogen phosphorylase and PDH during maximal intermittent exercise. Am. J. Physiol. Endocrinol. Metab. 1999, 277, E890-E900. [CrossRef]

26. Bogdanis, G.C.; Nevill, M.E.; Boobis, L.H.; Lakomy, H.K.; Nevill, A.M. Recovery of power output and muscle metabolites following $30 \mathrm{~s}$ of maximal sprint cycling in man. J. Physiol. 1995, 482, 467-480. [CrossRef] [PubMed]

27. Tomlin, D.L.; Wenger, H.A. The relationship between aerobic fitness and recovery from high intensity intermittent exercise. Sports Med. 2001, 31, 1-11. [CrossRef]

28. Spencer, M.; Fitzsimons, M.; Dawson, B.; Bishop, D.; Goodman, C. Reliability of a repeated-sprint test for field-hockey. J. Sci. Med. Sport 2006, 9, 181-184. [CrossRef]

29. Stanula, A.; Roczniok, R. Game intensity analysis of elite adolescent ice hockey players. J. Hum. Kinet. 2014, 44, 211-221. [CrossRef] [PubMed]

30. Eisenhofer, G.; Kopin, I.J.; Goldstein, D.S. Catecholamine metabolism: A contemporary view with implications for physiology and medicine. Pharmacol. Rev. 2004, 56, 331-349. [CrossRef]

31. Stanula, A.; Gabryś, T.; Roczniok, R.; Szmatlan-Gabryś, U.; Ozimek, M.; Mostowik, A. Quantification of the demands during an ice-hockey game based on intensity zones determined from the incremental test outcomes. J. Strength Cond. Res. 2016, 30, 176-183. [CrossRef] [PubMed] 